\title{
Влияние эколого-ценотических условий на рост и изменение продукционных параметров берез в условиях золоотвала тепловой электростанции
}

\section{Influence of habitat on growth and changes in productivity parameters of birch trees at the ash dump of power station}

\author{
Калашникова И. В., Мигалина С. В. \\ Kalashnikova I. V., Migalina S. V. \\ Ботанический сад Уральского отделения Российской академии наук, г. Екатеринбург, Россия. \\ E-mail: iren.kalachnikova@gmail.com \\ Institute Botanic Garden, Ural Branch, Russian Academy of Sciences, Ekaterinburg, Russia
}

\begin{abstract}
Peферат. Исследовались радиальные приросты, линейные параметры и биомасса ствола Betula pendula Roth и $B$. pubescens Ehrh., произрастающих в культурных и естественных древостоях на золоотвале Рефтинской ГРЭС. Показано, что независимо от условий у берез в возрасте 5-6 лет начинается активный рост ствола по диаметру. При переходе к стадии смыкания крон и увеличении конкурентной нагрузки березы из разных экотопов имели близкие значения ширины годичных колец. На данном этапе онтогенеза у берез, естественно возобновляющихся на зольном субстрате, отмечены более низкие линейные параметры ствола и доля стволовой древесины по сравнению с культурами. Сделан вывод о том, что на ранних этапах развития эколого-ценотические условия не оказывали влияния на ростовые процессы берез, а на более поздних стадиях у деревьев, произрастающих на золе, происходило изменение продукционных параметров, связанное с адаптацией к дефициту азота.
\end{abstract}

Ключевые слова. Адаптация, золоотвал, продукционные параметры, радиальный прирост ствола, Betula pendula, Betula pubescens.

Summary. Stem radial increments, linear parameters and biomass of Betula pendula Roth and B. pubescens Ehrh., growing in cultures and natural stands on the ash dump of the Reftinskaya power plant, were studied. It was shown that regardless of the conditions, the birch trees at the age of 5-6 years old had high increments in the stem diameter. During the transition to the stage of crown closure and the increase in the competitive load trees from different ecotopes had similar values of the width of annual rings. At this growth stage birch trees, which are naturally renewed on the ash substrate, have lower stem linear parameters and stem wood proportion in comparison with trees in cultures. It was concluded that at the early stages of development, ecological and cenotic conditions did not affect the growth processes of birch trees, whiles at later stages changes in production parameters associated with adaptation to nitrogen deficiency, were found in trees growing at the ash dump.

Key words. Adaptation, ash dump, Betula pendula, Betula pubescens, productivity parameters, stem radial increment.

Оценка устойчивости лесообразующих видов и лесных экосистем в условиях техногенного воздействия является одной из центральных задач современной экологии. Особое значение имеют исследования, выполненные на промышленных отвалах, многие из которых, например, золошлакоотвалы тепловых электростанций, не имеют аналогов в природе и оказывают широкое негативное воздействие на прилегающие территории (Махнев и др., 2002). Научной основой эффективной рекультивации техногенно нарушенных территорий является изучение адаптивного потенциала растений, способных произрастать на техноземах. К негативным свойствам зольного субстрата относятся высокая щелочность, дефицит доступных для растений форм азота, а также низкое содержание калия (Тарчевский, 1964; Махнев и др., 2002; Haynes, 2009). На Урале к числу пионерных древесных видов, активно заселяющих золоотвалы тепловых электростанций, относятся Betula pendula Roth и Betula pubescens Ehrh. 
(Махнев и др., 2002). Известно, что особенности морфологии и структуры биомассы служат индикаторами успешного развития растений в определенных условиях, в том числе на техногенных субстратах. В данной работе представлены результаты исследований продукционных параметров ствола $B$. pendula и B. pubescens, совместно произрастающих в условиях золоотвала тепловой электростанции.

Район исследований расположен в западной части Зауральской равнинной провинции, на границе южной тайги и лесостепи (Колесников и др., 1973). Исследовались 14-18-летние деревья B. pendula и B. pubescens, произрастающие в естественном ценозе и в культурах на золоотвале Рефтинской ГРЭС (N $57^{\circ} 07^{\prime}$; Е $\left.61^{\circ} 44^{\prime}\right)$, а также на расположенном вблизи золоотвала участке леса (Калашникова и др., 2011). В процессе создания культур на поверхность золы была нанесена смесь карьерного грунта и торфа (толщина слоя $0,45-0,65$ м), что привело к значительному улучшению условия почвенного питания растений по сравнению с чистой золой (Махнев и др., 2002). Почвогрунт в культурах по содержанию NPK и показателю $\mathrm{pH}$ незначительно отличался от верхних горизонтов лесных дерново-подзолистых почв. На участке естественного зарастания золоотвала отмечены начальные процессы почвообразования и снижение щелочности золы $(\mathrm{pH}=7,5-8,1)$ на фоне сохранения предельно низкой концентрации доступного для растений форм азота $(0,0005 \%)$ и низкого содержания калия $(0,003 \%)$, по сравнению с лесными почвами (Калашникова и др., 2017). Культуры характеризовались нормальным (симметричным) строением древостоя по диаметру ствола с преобладанием деревьев средних диаметров. В естественных ценозах распределение деревьев по диаметру имело значительную положительную асимметрию, что свидетельствует о наличии большого числа мелких деревьев и отражает длительность процесса формирования и неоднородность древесного яруса. При этом на участке леса, отличающемся высокой абсолютной полнотой и значительной густотой, березы рассматриваемой возрастной группы испытывали дополнительное конкурентное давление со стороны более крупных деревьев $B$. pendula, B. pubescens, Pinus sylvestris L., Salix caprea L., Populus tremula L. В ценозе на зольном субстрате древесный ярус отличался неравномерностью распределения по площади, при этом 14-летние березы занимали лидирующее положение в древостое.

Для определения продукционных параметров с каждого участка было отобрано по 10-25 деревьев $B$. pendula и $B$. pubescens семенного происхождения. Березы отбирались в пределах всего диапазона варьирования диаметров. Измеряли высоту, диаметр, биомассу ствола и ширину годичных колец. Надземную массу, а также относительную массу ствола (доля ствола от общей массы надземных органов) определяли после спиливания дерева и разделения его на фракции (ствол, ветви, листья, сухие ветви). Все данные по биомассе были рассчитаны на абсолютно сухой вес. Определение возраста деревьев и величины годичных приростов по диаметру осуществляли на поперечных спилах, отобранных у основания ствола, с использованием комплекса "LINTAB 6" (RINNTECH, Германия). Статистический анализ проведен с использованием критерия Манна-Уитни $(U)$ и Краскела-Уоллиса $(H)$. На рисунках приведены обобщенные данные для двух видов берез, поскольку значимых различий между видами по рассматриваемым параметрам ствола не отмечено.

Результаты исследований показали, что независимо от условий произрастания у берез в возрасте 5-6 лет начинался активный рост ствола по диаметру (рис. 1). При этом наиболее высокими величинами радиального прироста отличались деревья в культурах, что связано с более благоприятными условиями роста: низкой конкурентной нагрузкой и наличием плодородного слоя, нанесенного на поверхность золоотвала. Березы в естественных сообществах имели более низкую, по сравнению с культурами, ширину годичных колец. Однако это было обусловлено действием разных факторов. На зольном субстрате рост деревьев преимущественно ограничивался низким содержанием азота, в то время как на участке леса деревья развивались в условиях высокой конкуренции за свет. При переходе к стадии смыкания крон и усилении конкурентной нагрузки различия между березами из разных экотопов по величине годичного прироста становились менее выраженными.

Анализ развития ствола по диаметру и высоте показал, что на данном возрастном этапе модели роста берез на участке леса и в культурах были сходными, т.е. при одинаковом диаметре березы имели довольно близкие значения высоты (рис. 2А). При этом деревья в культурах отличались наиболее высокими средними диаметрами ствола $(U=86 ; p<0,0000)$. Модель роста деревьев в естественном ценозе на золе отличалась от лесного насаждения и культур в связи с более низкими средними значениями 
линейных параметров ствола (рис. 2А). Ранее также было показано, что древесные виды, произрастающие на золе, характеризуются более низкими размерами ствола, по сравнению с особями на рекультивированных участках (Чибрик и др., 2012).

Анализ индивидуальных особенностей роста деревьев на основе относительной высоты ствола (отношение высоты ствола к его диаметру) показал, что деревья на участке леса отличались наиболее высокими значениями данного параметра (рис. 2Б), что связано с усилением вертикального роста в условиях высокой конкурентной нагрузки (Khan et al., 2000; Собачкин и др., 2009). Ранее было отмечено,

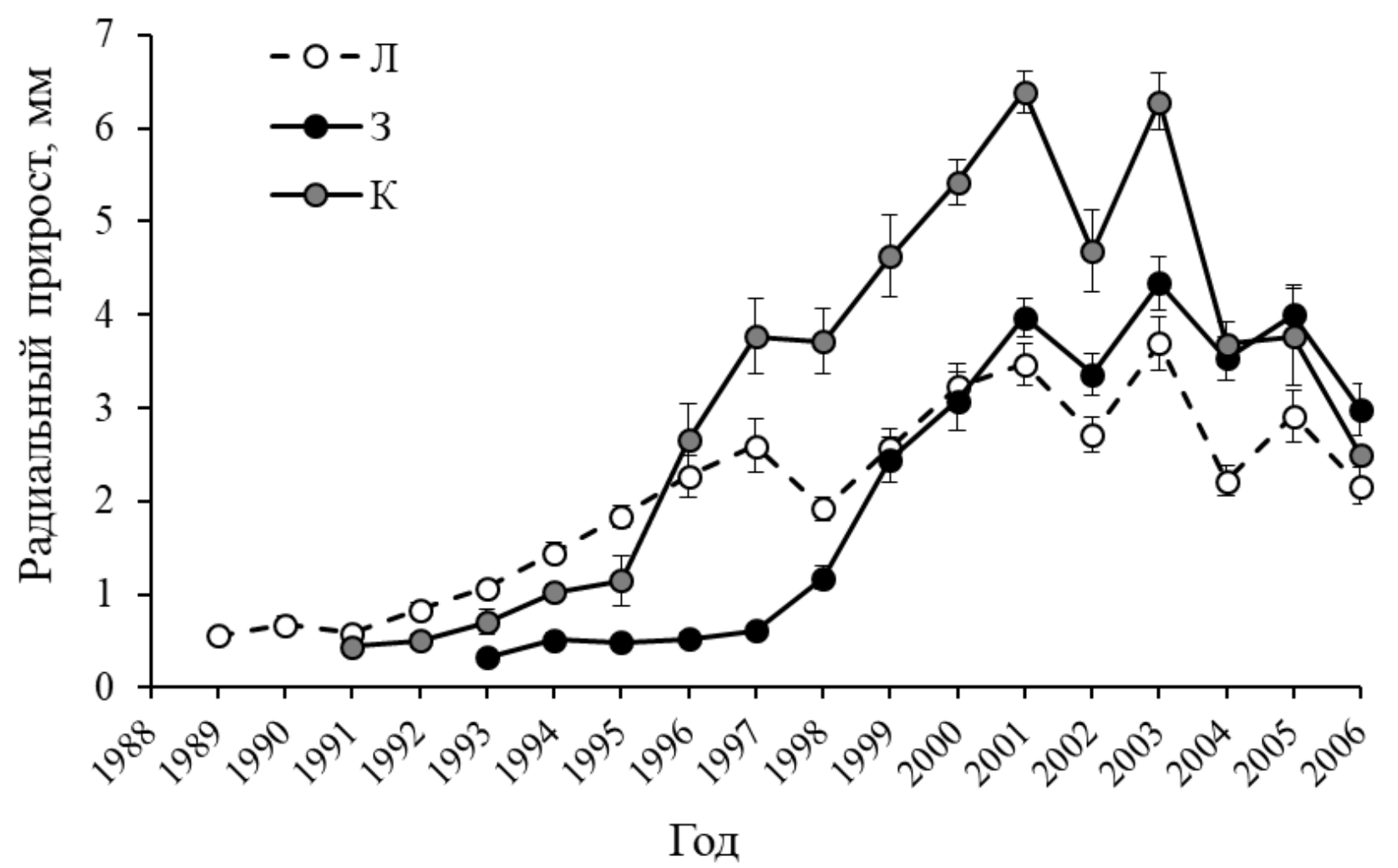

Рис. 1. Радиальные приросты ствола берез, произрастающих на лесных почвах (Л), на зольном субстрате (3) и в культурах на золоотвале (К).
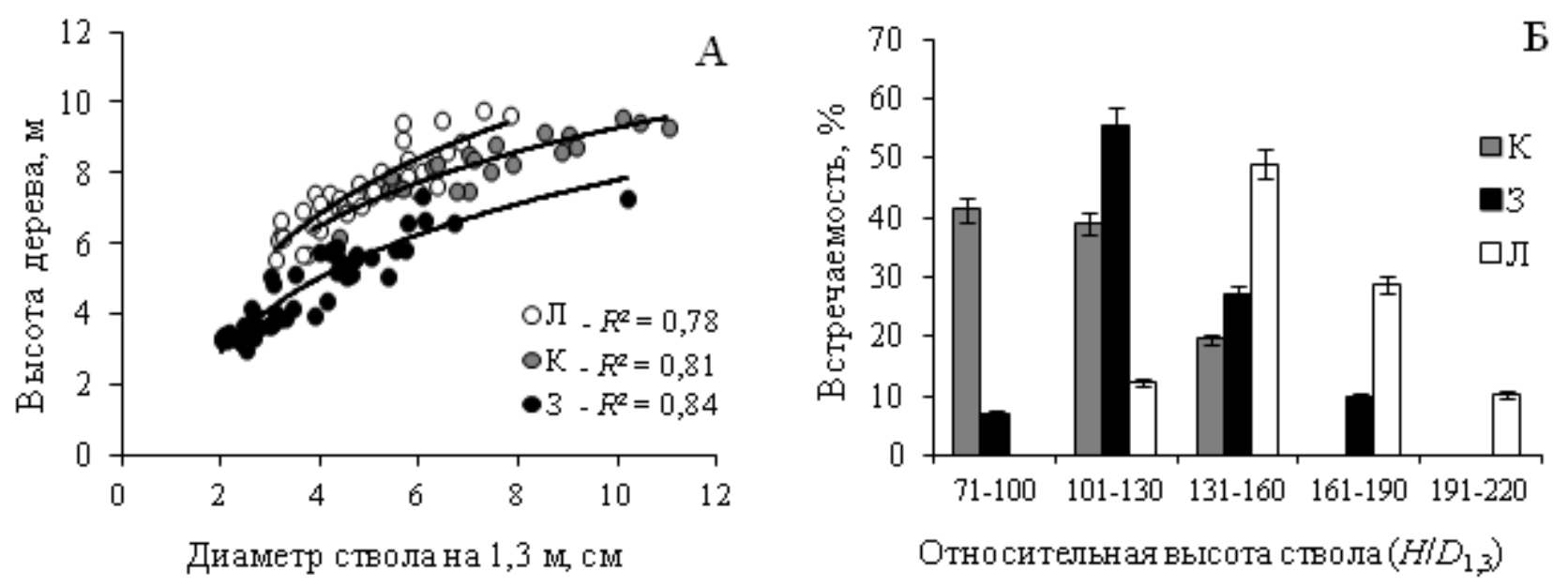

Рис. 2. Линейные параметры ствола берез (А) и распределение берез по относительной высоте ствола (Б) в разных экотопах: Л - участок леса, 3 - фитоценоз, формирующийся на зольном субстрате, К - культуры на золоотвале. 
что подобное нарушение сопряженности роста ствола вследствие более активного роста в высоту является основной стратегией деревьев в конкуренции за свет (Berntson, Wayne, 2000; Grams, Andersen, 2007). У берез на золе также отмечены большие значения относительной высоты, что связано с низкими линейными параметрами ствола. Снижение интенсивности роста ствола на зольном субстрате может быть вызвано уменьшением оттока фотосинтатов в ствол в условиях низкого содержания азота в субстрате (Argen, Franklin, 2003). В культурах деревья отличались низкой относительной высотой ствола, что связано с активным радиальным ростом в более благоприятных эколого-ценотических условиях, по сравнению с естественными ценозами.

У исследованных видов наблюдалось значительное изменение относительных параметров структуры биомассы в зависимости от условий произрастания $(H=77,2 ; p<0,0000)$. На участке леса березы отличались наибольшей относительной массой ствола $(75,2 \%)$ по сравнению с культурами $(U=97 ; p<0,0000)$ и деревьями в естественном ценозе на золе $(U=19 ; p<0,0000)$. Такое распределение биомассы, на наш взгляд, связано с необходимостью переноса ассимиляционного аппарата в более освещенную верхнюю часть древесного полога. Показано, что в условиях конкуренции за свет в высокоплотных насаждениях активный рост деревьев в высоту сопровождался увеличением распределения ассимилятов в ствол и возрастанием его относительной массы (Vanninen, Makela, 2005; Poorter et al., 2012). Самая низкая доля стволовой массы отмечена у берез, произрастающих на золе $(58,9$ \%). Ранее отмечалось, что в условиях недостатка почвенных ресурсов относительная масса ствола может уменьшаться (Argen, Franklin, 2003; Poorter et al., 2012) в результате увеличения распределения фотосинтатов в крону и корневую систему дерева (Trubat et al., 2006; Poorter et al., 2012). В культурах доля массы ствола в общей надземной массе дерева составляла около 69,0 \%.

Таким образом, полученные результаты показали, что на ранних этапах развития берез эколого-ценотические условия не оказывали влияния на ростовые процессы берез. При достижении стадии смыкания крон у Betula pendula и B. pubescens, естественно возобновляющихся на золе, уменьшалась интенсивность роста деревьев в высоту и по диаметру, а также снижалась доля ствола в общей надземной биомассе, что связано с уменьшением оттока ассимилятов и отражает адаптацию исследованных видов к росту в условиях дефицита азота. Создание более благоприятных эдафических условий в культурах способствовало интенсивному росту и накоплению стволовой биомассы берез.

Работа выполнена в рамках Государственного задания ФГБУН Ботанического сада Уральского отделения Российской академии наук.

\section{ЛИТЕРАТУРА}

Калашникова И. В. Нагимов 3. Я., Махнев А. К. Изменение структуры и фитомассы кроны березы повислой (Betula pendula Roth) и (B.pubescens Ehrh.) в условиях техногенного стресса // Вестник КрасГАУ, 2011. - № 10. C. $123-126$.

Калашникова И. В., Мигалина С. В., Иванова Л. А., Иванов Л. А. Структурно-функциональная адаптация фотосинтетического аппарата берез к условиям золоотвалов тепловых электростанций // Экспериментальная биология растений: фундаментальные и прикладные аспекты: сб. матер. годичного собрания Общества физиологов растений России науч. конф. и школы для молодых ученых (18-24 сентября 2017 г., Крым, г.Судак.). - Москва, 2017. - C. 180.

Колесников Б. П. Зубарева Р. С., Смолоногов Е. П. Лесорастительные условия и типы лесов Свердловской области: практ. руководство. - Свердловск: УНЦ АН СССР, 1973. - 176 с.

Махнев А. К., Чибрик Т. С., Трубина М. Р. Лукина Н. В., Гебель Н. Э., Терин А. А., Еловиков Ю. И., Топорков $\boldsymbol{H}$. В. Экологические основы и методы биологической рекультивации золоотвалов тепловых электростанций на Урале. - Екатеринбург: УрО РАН, 2002. - 356 с.

Собачкин Д. С., Бенькова В. Е., Собачкин Р. С., Бузыкин А. И. Влияние густоты на таксационные показатели сосновых молодняков естественного и искусственного происхождения // Лесоведение, 2009. - № 2. - С. 3-9.

Tарчевский В. В. Биологические методы консервации золоотвалов тепловых электростанций Урала // Растения и промышленная среда: сб. науч. тр. - Свердловск: УрГУ им. Горького, 1964. - Сб. 1. - С. 70-115.

Чибрик Т. С., Лукина Н. В., Филимонова Е. И., Глазырина М. А. Структура и динамика лесных фитоценозов на нарушенных промышленностью землях // Изв. Самар. НЦ РАН, 2012. - Т. 14, № 1(5). - С. 1403-1406. 
Agren G. I., Franklin O. Root : shoot ratios, optimization and nitrogen productivity // Annals of Botany, 2003. - Vol. 92. - P. 795-800.

Berntson G. M., Wayne P. M. Characterizing the size dependence of resource acquisition within crowded plant populations // Ecology, 2000. - Vol. 81. - P. 1072-1085.

Haynes R. J. Reclamation and revegetation of fly ash disposal sites - Challenges and research needs // J Environ Manage, 2009. - Vol. 90(1). - P. 43-53.

Grams T. E. E., Andersen C. P. Competition for resources in trees: physiological versus morphological plasticity // Progress in Botany, 2007. - Vol. 68. - P. 356-381.

Khan S. R., Rose R., Haase D. L., Sabin T. E. Effects of shade on morphology, chlorophyll concentration, and chlorophyll fluorescence of four Pacific Northwest conifer species // New Forests, 2000. - Vol. 19. - P. 171-186.

Poorter H., Niklas K. J., Reich P. B., Oleksyn J., Poot P., Mommer L. Biomass allocation to leaves, stems and roots: meta-analyses of interspecific variation and environmental control // New Phytologist, 2012. - Vol. 193. - P. 30-50.

Trubat R., Cortina J., Vilagrosa A. Plant morphology and root hydraulics are altered by nutrient deficiency in Pistacia lentiscus (L.) // Trees, 2006.- Vol. 20, № 3. - P. 334-339.

Vanninen P., Makela A. Carbon budget for Scots pine trees: effects of size, competition and site fertility on growth allocation and production // Tree Physiol., 2005. - Vol. 25. - P. 17-30. 